threne in mice have, within each species, tissue-specific antigens. The immunological reactions of the host against these tumours as detected in vitro are similar to those observed in man. Immunization by bladder cancer cells from mice of the same strain reduced the induction of bladder cancer by methylcholanthrene. This is an unexpected finding, because hitherto tumours induced by chemical carcinogens had individually unique antigens and did not cross-react with other tumours produced in a similar tissue by the same chemical. It will be of great interest to see if this observation holds true for bladder cancers induced by other bladder carcinogens and by oral as well as intravesical exposure to the agent.

1 Bubenik, J., Perlmann, P., Helmstein, K., and Moberger, G.; International

Fournal of Cancer, 1970, $5,39$.
Bubenik, J., Perlmann, P., Helmstein, K., and Moberger, G., International

Fournal of Cancer, 1970, 5, 310.
3 Hellström, I., Hellström, K. E., Siögren, H. O., and Warner, G. A., International fournal of Cancer, 1971, 7, 1 .

- Tanaka, T., Cooper, E. H., and Anderson, C. K., European fournal of Clinical and Biological Research, 1970, 15, 1084

5 Sarma, K. P., Fournal of Urology, 1970, 104, 843.

- Olsson, C. A., Rao, C. N., Menzoian, J. O., and Byrd, W. E., Fournal of Urology, 1972, 107, 607 .

7 Taranger, L. A., Chapman, W. H., Hellström, I., and Hellström, K. E., Science, 1972, 176, 1337.

\section{P.H.L.S. Monographs}

The Public Health Laboratory Service has achieved a standard of diagnostic bacteriological work probably unsurpassed on such a scale in any other country. In a unified Service holding regular staff meetings it has been possible for directors of laboratories to exchange ideas about methods, some modifications of which, so far from having been published, have not even been committed to paper. It has therefore been decided to publish a series of monographs embodying this information for the benefit both of the Service and of other laboratories engaged in such work. Sir James Howiel writes in a preface to the first of these, on "Laboratory Diagnosis of Venereal Disease,": "During our discussions on preparing the series, it became evident that our half-hidden treasures included not only methods that were used within the P.H.L.S. but also fragments and even substantial bodies of unpublished scientific work which were taken for granted within the Service but which had never been made generally known." He also writes that the object is not to "duplicate or replace standard textbooks." In fact there are no books in which the best methods of performing particular investigations are so exhaustively described by authors with special experience of them. The nearest existing approach to this venture is the series of "Broadsheets" of the Association of Clinical Pathologists, which covers a much wider field in publications of a more condensed form.

The subjects of the first three of these monographs, now published simultaneously, will appeal in different ways and to different people. No. 1 , on the laboratory diagnosis of venereal disease, is naturally by $A$. E. Wilkinson and his colleagues of the Venereal Disease Reference Laboratory at the London Hospital, and includes a full description of five distinct serological tests for syphilis, some of which are unlikely to be attempted in most laboratories. More helpful to them is the very detailed account which follows, by D. A. McSwiggan and C. E. D. Taylor, of a "simplified" complement-fixation test. Methods for the diagnosis of gonorrhoea include instructions for two methods of determining penicillin sensitivity, of which the plate dilution method appears preferable to that employing discs. In the diagnosis of trichomoniasis emphasis is laid on the greater sensitivity of cultivation, for which the medium used contains chloramphenicol, gentamicin, and amphotericin. That recommended for growing gonococci contains vancomycin, colistin, and nystatin, with or without trimethoprim. The achievements of antibiotics in getting rid of unwanted bacteria in cultures are no less remarkable in their small way than their capacity to cure disease.

No. 2, on "The Use of Chemical Disinfectants in Hospitals," is by J. C. Kelsey and Isobel M. Maurer, and embodies the distilled experience gained since the establishment of the Disinfection Reference Laboratory under Kelsey in 1960. The preface to this refers to "the large number of written and oral inquiries" on this subject which reach the Service, and it is doubtless felt that in future such approaches can be met by simply referring the inquirer to this publication. It gives an account of the properties of different disinfectants, not omitting their costs, and some of their manifold uses. Instead of laying down the law themselves about optimum methods the authors have reproduced in full the "disinfectant policies" adopted by six hospitals or hospital groups, each giving instructions for the chemical disinfection of everything from baths to urinals in alphabetical order, among which the reader must evidently make his own choice. This can be somewhat varied; for heat-sensitive cystoscopes it lies between pasteurization, chlorhexidine, ethylene oxide, glutaraldehyde, and reference to Broadsheet No. 1 of the A.C.P. "Disinfectant testing in a hospital should be restricted to in-use testing"-that is, cultivation of solutions in use to determine whether they actually contain living bacteria, as they often do if overdiluted by ward staff or too seldom changed.

The subject of No. 3 is "Anaerobic Infections," by A. T. Willis. This gives an excellent account of methods of securing anaerobiosis, of culture media required for special purposes, and of the characters of Clostridia; a full-page table gives those of 19 "commonly encountered" species. It refers only briefly to the Gram-negative anaerobic bacilli (Bacteroides, etc.), and it would seem to be mainly to these to which the preface refers in writing of the "technical difficulties in their isolation and identification" and the "confused state of their taxonomy and nomenclature." In any future edition this section might with advantage be expanded.

\footnotetext{
Public Health Laboratory Service Monograph Series, Nos. 1-3 issued.
} London, H.M.S.O., 1972.

\section{Weightless Bones}

Patients who are bedridden for long periods suffer from, among other effects, loss of mineral matter from the bones. A similar effect results from prolonged weightlessness in space. Consequently, studies of it in astronauts may help people who lead more mundane lives.

At the recent International Astronautical Congress in Vienna $^{1}$ Dr. Stephen Hully, of the United States Public Health Service Hospital, San Francisco, described how he and three colleagues kept 34 healthy males in bed for periods varying from 17 to 36 weeks, allowing them to raise their 
heads not more than $30^{\circ}$ above the horizontal when feeding or during evacuations, but otherwise keeping them completely recumbent, though they could move as much as they liked in the horizontal plane

It was found by means of gamma-ray absorptiometry that the mineral loss affected mainly the weight-bearing bones, especially the calcaneus, whereas the radius and ulna were not affected at all. Without treatment the rate of calcium loss from the body was about $0.5 \%$ of the whole body store per month, the mean rate being $190 \mathrm{mg}$ per day, while the diet contained $1.0 \mathrm{~g}$ of calcium and $1.6 \mathrm{~g}$ of phosphorus per day. When the man got up again, the calcaneus recovered its mineral content slightly faster than the previous rate of loss.

Six methods of treatment were tried to prevent the mineral loss. Conventional exercises for a total of 80 minutes per day were found to have no effect. Longitudinal static compression between the soles of the feet and the iliac crest, with a special "gravitation simulating" suit applying $80 \%$ of the compression which gravity would cause, was tried for four hours a day continuously on some of the men and on others intermittently 45 times a minute for four to six hours a day with 80 to $100 \%$ of gravitational compression. But this simulation of gravity, the authors state, "provided at best a limited degree of protection."

As to supplementing the diet, calcitonin was tried but had no beneficial effect. Phosphate, given as the neutral potassium salt at the rate of $1.3 \mathrm{~g}$ of phosphorus per day, prevented hypercaliuria but did not reduce the overall mineral loss. But this dose of phosphorus combined with calcium lactate giving 0.8 or $1.3 \mathrm{~g}$ of calcium per day maintained the mineral balance and prevented loss of mineral from the calcaneus for the first 10 weeks-but not, apparently, during the fourth and final month of bed rest. The authors therefore recommend a high intake of calcium and phosphorus for prolonged space flights.

1 Hully, S., Lockwood, D., Donaldson, C., and Vogel, J., "Bone Mineral Loss during Prolonged Bed Rest," 23rd International Astronautical Congress, Vienna, 1972. To be published by D. Reidel Publishing Co., Congress, Vienna, 1972
Dordrecht, Holland.

\section{Inquiry into G.M.C.}

The Government's announcement last week that it will set up a committee of inquiry into the structure and functions of the G.M.C. was inevitable once it was clear that the profession no longer was likely to reach agreement within itself. The decision must now be seen as providing an opportunity to look at the question in a fresh spirit. Presumably the report of the Brynmor Jones Committee on the G.M.C.'s structure will be high on the agenda for the new committee of inquiry to consider. Doctors will note with satisfaction the assurance that Sir Keith Joseph gave when announcing the inquiry that it was not contemplated that the profession should be regulated otherwise than by a predominantly professional body.

Though it is occasional doctor's follies or delinquencies that bring the G.M.C. most dramatically before the public eye, its responsibility for educational standards is the real basis of its existence. It is the training he has undergone to the satisfaction of his teachers that distinguishes a registered doctor from a quack, and it was to make this distinction for the public benefit that the Government of the day established the G.M.C. under the Act of 1858-to the cheers of the medical profession. Now that the hazards as well as the benefits of medicine have multiplied 10 times over the control of educational standards must be the primary duty of the G.M.C. or its successor. From this starting point the committee of inqury can have a fruitful examination of how the G.M.C. can best be composed to command the respect of the medical profession and to serve the interests of its patients.

\section{Trends for Scientific Journals}

Doctors who try to "keep up with the literature" may take some comfort from findings reported last week to a conference of scientific editors at the Royal Society. Full-time research workers, it appears, can stay abreast of their subject by taking on average no more than 12 of the hundreds of journals in that field, and even in the case of these "core" journals they look at only between $4 \%$ and $17 \%$ of the pages. This selection of the small proportion of relevant material from the mass of published work is accepted as inevitable by scientists, so the practising clinician should not be surprised if many of the original articles in medical journals are not applicable to his day-to-day work. This must be so since in any one clinical discipline important research findings are relatively rare events. The biological, earth, and physical sciences were all represented at the meeting, and there was little dissent from the findings of $\mathrm{Dr}$. $\mathrm{K}$. L. Blaxter that in any given field of interest $90 \%$ of important original work is published in a handful of journals; that this core of journals is also the starting point for searches of literature (rather than abstracting journals or indexing services); and that at least in western countries photocopying is rapidly making the reprint obsolete.

The steady growth in numbers of scientific journalsdoubling about every 25 years-may seem less alarming in the light of this assessment, but there was no doubt that it worried the meeting. There was strong criticism of the mushroom growth of trivial new journals. One reason for their proliferation, according to Sir Harold Thompson, was that "commercial publishers offer young men financial inducements to act as editors or to sit on editorial boards." Professor H. L. Kornberg revived the idea that journals should publish only extended abstracts of scientific work and that the full text should be deposited in a central library, which could provide photocopies on request. There was little enthusiasm for this scheme, though it seems to be widely used in the U.S.S.R. and in Eastern Europe. Several speakers with experience of systems in Britain for the deposit of detailed basic data not published with a paper reported that such data were hardly ever consulted; but publication of essential data is mandatory if the paper is to be critically assessed and commented on in subsequent correspondence. Certainly no collection of extended abstracts can make attractive reading-surely one of the best features of scientific journals is their browsing potential?

Long-term trends are difficult to forecast in the field of scientific publications. In retrospect no one is surprised that prepublication clubs have burnt themselves out and that publication of verbatim conference proceedings has virtually ceased, though neither event seemed certain even three years ago. But it does seem unlikely that the present growth rate 